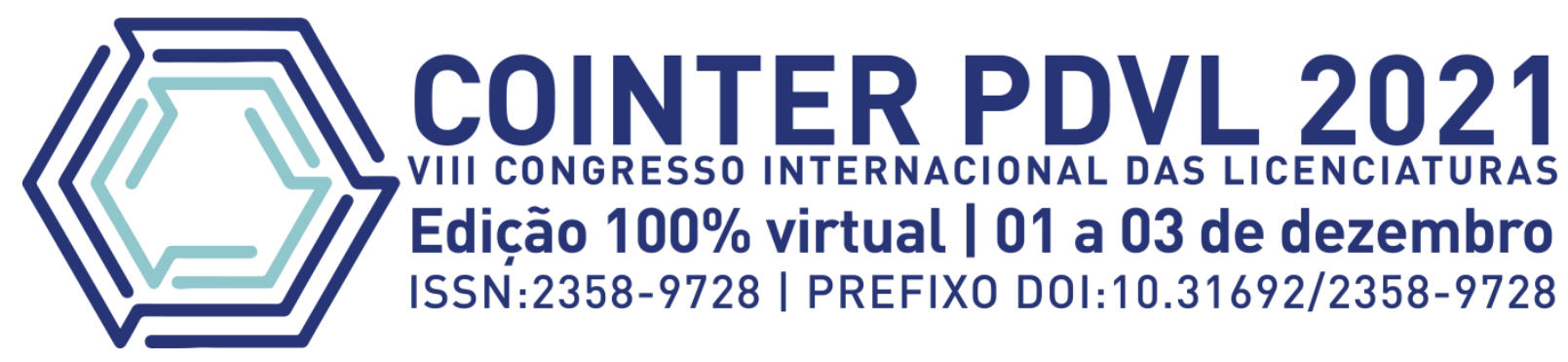

\title{
MATERIALIAÇÃO DA PROPOSTA DE AVALIAÇÃO NA FORMAÇÃO DE PROFESSORES DE QUÍMICA DA REDE FEDERAL
}

\section{MATERIALIZACIÓN DE LA PROPUESTA DE EVALUACIÓN EN LA FORMACIÓN DE PROFESORES DE QUÍMICA EN LA RED FEDERAL}

\section{MATERIALIZATION OF THE EVALUATION PROPOSAL IN THE TRAINING OF CHEMISTRY TEACHERS IN THE FEDERAL NETWORK}

\author{
Apresentação: Comunicação Oral \\ Sabrina Kelly Andrade de Oliveira ${ }^{1}$; Manuelle Patrícia Ramos Vieira ${ }^{2}$
}

DOI: https://doi.org/10.31692/2526-7701.VIIICOINTERPDVL.0462

\section{RESUMO}

A presente pesquisa tem por objetivo compreender a materialização da avaliação na formação de professores de Química no tocante as prÁticas avaliativas do Projeto Pedagógico do Curso (PPC) e as Concepções de Avaliação, abordadas por Guba e Lincoln, com foco nas Gerações da Avaliação. Para a obtenção de dados foi feita uma exígua amostragem com a aplicação de um formulário contendo quatro questonionamentos sobre a avaliação em sua sala de aula para professores da Rede Federal de Ensino. Os resultados obtidos foram tabulados e analisados, permitindo a observação da conformidade, entre as palavras dos professores e o Projeto Pedagógico do Curso, relacionado a materialização deste e as múltiplas dimenssões da avaliação, compreendidas nas perspectivas formativa, diagnóstica e somativa. Após a análise percebeu-se uma inclinação dos respondentes a uma avaliação de segunda e terceira geração.

Palavras-Chave: Avaliação; Aprendizagem; Formação de professores.

\section{RESUMEN}

Esta investigación tiene como objetivo comprender la materialización de la evaluación en la formación de los docentes de Química sobre las prácticas evaluativas del Proyecto del Curso Pedagógico (PPC) y los Conceptos de Evaluación, abordados por Guba y Lincoln, con un enfoque en las Generaciones de Evaluación. Para la obtención de datos se realizó una pequeña muestra con la aplicación de un formulario que contiene cuatro preguntas sobre la evaluación en su aula para docentes de la Red Federal de

\footnotetext{
${ }^{1}$ Licencianda em Química, IFPE campus Vitória de Santo Antão, sabrinak10319@gmail.com

${ }^{2}$ Mestre em Educação, Secretaria de Educação de Pernambuco, manuelleprvieira@ gmail.com
} 
Educación. Los resultados obtenidos fueron tabulados y analizados, permitiendo observar la conformidad entre las palabras de los docentes y el Proyecto Pedagógico del Curso, relacionado con su materialización y las múltiples dimensiones de la evaluación, entendida en las perspectivas formativa, diagnóstica y sumativa. Después del análisis, se notó una inclinación de los encuestados a una evaluación de segunda y tercera generación.

Palabras Clave: Evaluación; Aprendiendo; Formación de profesores.

\section{ABSTRACT}

This research aims to understand the materialization of evaluation in the formation of Chemistry teachers regarding the evaluative practices of the Pedagogical Course Project (PPC) and the Evaluation Concepts, addressed by Guba and Lincoln, with a focus on Evaluation Generations. To obtain data, a small sample was made with the application of a form containing four questions about the assessment in their classroom for teachers from the Federal Education Network. The results obtained were tabulated and analyzed, allowing the observation of conformity between the words of the teachers and the Pedagogical Project of the Course, related to its materialization and the multiple dimensions of the evaluation, understood in the formative, diagnostic and summative perspectives. After the analysis, an inclination of respondents to a second and third generation assessment was noticed.

Keywords: Evaluation; Learning; Teacher training

\section{INTRODUÇÃO}

A presente pesquisa busca perceber a materialização da avaliação na formação de professores referente às questões da avaliação da aprendizagem, fazendo relação entre as questões de suas práticas avaliativas com o Projeto Pedagógico do Curso, bem como com as Concepções de Avaliação, trazidas por Guba e Lincoln, com foco na Quarta Geração. Visando assim, contribuir com as pesquisas voltadas ao tema em sua prática de sala de aula.

O ato de avaliar é visto como uma ação pedagógica de suma importância, no processo de ensino e de aprendizagem, pois permite que o professor analise a metodologia utilizada, percebendo se está sendo assertivo ou não, o que o possibilita a fazer os ajustes das incoerências que estejam ocorrendo em sua ação pedagógica. Sendo assim, a Avaliação é vista como um processo evolutivo de construção e reconstrução constante.

Ao longo da história, a avaliação foi tratada como um meio de mensuração, de memorização, bem como um meio de tortura e premiação. De acordo com Guba e Lincoln (1989), a avaliação foi classificada em três gerações: Primeira Geração da Avaliação: Mensuração; Segunda Geração da Avaliação: Descrição; Terceira Geração da Avaliação: Juízo de valor.

A primeira geração da avaliação é considerada uma pré-avaliação, pois a era tida como 
um instrumento de mensuração, utilizada para medir o quanto o estudante estava dominando o conteúdo ensinado pelo professor. Seus primeiros exames eram aplicados oralmente, exigindo do estudante a proeza de memorizar e repetir as palavras ditas pelo professor em sala de aula, assim só os que fossem portadores da boa memória se sobressairiam.

A segunda geração da avaliação é caracterizada pela descrição dos padrões, com a evidência dos pontos fortes e fracos de determinado objetivo estabelecido. Nesse sentido, o professor pré-determina e controla o ensino, avaliando ao final do processo, buscando ainda uma padronização comportamental. Para reforçar os comportamentos positivos eram utilizadas premiações e castigos aos comportamentos negativos.

A terceira geração da avaliação se caracterizou pela iniciativa de alcançar o Juízo de Valor, em que o avaliador seria o julgador, mantendo as mesmas funções técnicas e descritivas da geração anterior. O professor tem a preocupação com a compreensão do estudante, com os erros e os acertos cometidos, fazendo a avaliação durante o processo, sendo esta diagnóstica, qualitativa, processual e reguladora.

Para os autores Gubba e Lincoln (1989), as três gerações apresentavam no mínimo três incoerências: a tendência a generalização, a incapacidade de acomodar o pluralismo de valores e o comprometimento exagerado com o paradigma científico da investigação - qualquer coisa que tenha respaldo da avaliação positiva é pregada como sendo a coisa certa a fazer. Diante disso, os autores propuseram uma quarta geração.

A quarta geração propõe uma avaliação que quebre os parâmetros e os limites estabelecidos a priori pelas três primeiras gerações, sendo um processo interativo e negociado que envolve grupos de interesses. Assim, diferentes grupos de interesses terão diferentes reivindicações, preocupações e questões, sendo responsabilidade do avaliador compreendê-las e abordá-las em sua avaliação, obtendo sua raiz nos moldes de investigação, sendo uma alternativa ao paradigma científico.

Na geração da Negociação, o estudante é visto como o centro das ações avaliativas, sendo ativo e emancipado, tomando junto ao professor a responsabilidade no ato avaliativo podendo decidir, através da negociação, qual o desenvolvimento do processo avaliativo. Assim, o professor se preocupa com a compreensão do estudante e não apenas em sua capacidade de reprooduzir o que foi trabalhado em sala de aula.

A Proposta Pedagógica do Curso de Licenciatura Plena em Química prevê uma Avaliação contínua, assumindo de forma integrada as funções diagnóstica, processual, formativa e somativa, que devem ser utilizadas como princípios para a tomada de consciência da prática, levando em consideração o predomínio dos aspectos qualitativos sobre os 
quantitativos.

Diante do exposto, reafirmamos que esta pesquisa tem por objetivo geral analisar a materialização da proposta avaliativa contida no PPC da formação de professores de Química, refletindo acerca dos limites e possibilidades.

Os objetivos específicos foram definidos de modo a conduzirem o trabalho para o alcance do objetivo geral, que são: categorizar a perspectiva da avaliação no PPC da Licenciatura em Química da Rede Federal de acordo com as Gerações da Avaliação e identificar as práticas avaliativas do professor e suas relações com as orientações contidas no PPC.

\section{FUNDAMENTAÇÃO TEÓRICA}

Guba e Lincoln (1989), trazem um esboço sobre os vários significados da Avaliação, que é totalmente influenciada pelos contextos histórico, cultural, filosófico, sociológico de cada época, repartindo assim, em três gerações de Avaliação e, sugerindo ainda, uma quarta geração de Avaliação.

A primeira geração da avaliação é considerada uma pré-avaliação, pois no período, era tida apenas como um instrumento de mensuração, utilizado para medir o quanto o estudante estava dominando o assunto. Essencialmente como um teste de memória. A escola ensinava as crianças o que lhe era tido por certo, para exibir um certo domínio, com avaliadores superiores e detentores de toda a verdade sobre a ciência.

Os primeiros exames eram aplicados oralmente, exigindo do estudante uma dissertação sobre o que foi trabalhado, assim só os que fossem portadores da boa memória se sobressairia. Rice (1897) observou que as escolas gastavam muito tempo com o "ensino básico" e desenvolveu um teste ortográfico, com os dados sobre o aproveitamento do estudante a fim de assim tornar as escolas competentes.

Em contrapartida, Alfred Binet (1912) criou um teste que separaria as crianças que estavam atrapalhando o aprendizado das outras crianças, tidas como normais, o Teste de Quoeficiente de Inteligência (Q.I.). Com essa criação e aprimoramento do "quoeficiente de inteligência” (Q.I.), os testes passaram a ser vistos como meio de determinar se o avaliado estava ou não atendendo as expectativas, separando-o dos outros. Esses conteúdos eram intrinsecamente preparatórios para a faculdade.

Após a primeira guerra mundial notou-se que o método de avaliação da primeira geração não satisfazia mais os currículos escolares, pois os dados se limitavam aos estudantes. Nesse período, os estudantes visavam a escola como o meio de obtenção de elementos para ultrapassar a posição social e econômica de seus pais, porém as escolas estavam mal preparadas. 
Na segunda geração, através do programa "eigth-year study" que visava estudar se o conceito de que os currículos mal preparados das escolas influenciariam no desempenho do estudante na Universidade, a aprimoração do programa através dos estudos de Tyler ("pai da avaliação"), foram criados os chamados “objetivos", que eram os resultados desejados. Assim, Tyler tinha como propósito para a avaliação aperfeiçoar o currículo e confirmar se eles estavam funcionando.

As avaliações eram aplicadas curso a curso, coletando informações sobre o nível de aproveitamento do estudante e assim aperfeiçoando o currículo até a um nível apropriado. Sendo assim, a segunda geração da avaliação é caracterizada pela descrição de padrões de pontos fortes e fracos de determinado objetivo estabelecido. E, a partir de então, a mensuração deixou de ser tratada como avaliação, passando a ser considerada como instrumento utilizado a serviço da avaliação.

Com o lançamento do Sputnik, a abordagem descritiva da segunda geração se mostrou ineficaz, mostrado pela desvantagem dos EUA em detrimento a Rússia, na corrida espacial. Assim, a terceira geração da avaliação se caracterizou pela iniciativa de alcançar o juízo de valor, onde o avaliador seria o julgador, mantendo as funções técnicas e descritivas de anteriores.

Tendo em vista os vários problemas das gerações anteriores, a terceira geração aborda o próprio objetivo da avaliação como algo problemático. Foram desenvolvidos vários modelos para essa geração, para todos esses métodos distintos o juízo de valor era parte essencial da avaliação.

Para o autor as três gerações apresentam no mínimo três incoerências que são: Tendência ao generalismo (conluio entre administrador e avaliador); Incapacidade de acomodar o pluralismo de valores (as primeiras gerações não levam em conta as diferenças de "valores"); Comprometimento exagerado com o paradigma científico de investigação (descontextualização do objeto de avaliação; exagerada dependência em relação à mensuração quantitativa formal; qualquer coisa que tenha respaldo da avaliação positiva é pregada como sendo a coisa certa a fazer; liberando o avaliador de qualquer responsabilidade moral).

Em resposta aos problemas das três gerações Guba e Lincoln (1989) propõe uma quarta geração da avaliação, trazendo uma "abordagem alternativa" que eles chamaram de "avaliação construtiva responsiva", em que o termo responsivo refere-se a maneira, os parâmetros e os limites da avaliação. Os autores chegaram à conclusão que nas três primeiras gerações os parâmetros e limites foram estabelecidos a priori. A avaliação responsiva estabelece parâmetros e limites por meio de um processo interativo e negociado que envolve grupos de interesses. $\mathrm{O}$ 
termo construtivo utilizado para designar a metodologia usada para conduzir a avaliação, sua raiz encontra-se nos moldes de investigação, uma alternativa ao paradigma científico.

Os autores nos apresentam algumas ideias que vão representar o método responsivo de focalizar e o método construtivista de conduzir. Quanto ao método responsivo de focalizar, Guba e Lincoln, diz ser baseado em reivindicações, preocupações e questões em relação ao objeto de avaliação (reivindicação é qualquer alegação apresentado por um interessado que seja favorável ao objeto de avaliação; preocupação é qualquer afirmação que um interessado venha a apresentar que seja desfavorável ao objeto de avaliação; questão diz respeito a qualquer situação sobre a qual pessoas sensatas possam discordar).

Diferentes grupos de interesses terão diferentes reivindicações, preocupações e questões, é responsabilidade do avaliador compreendê-las e abordá-las em sua avaliação.Eles identificam três tipos de grupos de interesses, os representantes, que são as pessoas envolvidas na produção e implementação do objeto da avaliação; os beneficiários, que são as pessoas que de alguma maneira tiram proveito do uso do objeto de avaliação e as vítimas, que são as pessoas que são afetadas negativamente pelo uso do objeto de avaliação.

A avaliação responsiva busca obter um consenso entre todas as reivindicações, preocupações e questões dos diferentes grupos de interesses, porém isso o é em teoria. Em prática seria uma tomada de decisão em conjunto, onde o avaliador seria o moderador das discussões. Esse tipo de avaliação apresenta quatro fases: na primeira, os grupos de interesse são identificados e solicitado a apresentação das reivindicações, preocupações e questões que desejarem; na segunda, as reivindicações, preocupações e questões levantadas pelos grupos são apresentadas para que todos os outros grupos comentem, refutem, concordem ou rejeitem da maneira que lhes apraz; na terceira, as reivindicações, preocupações e questões que não foram resolvidas cumprem a função de organizadores para coleta de informações pelo avaliador; na quarta, ocorre a negociação entre os grupos de interessados, mediado pelo avaliador e provido das informações avaliatórias coletadas, com finalidade de alcançar um consenso sobre o ponto de discórdia. Nem todos os pontos poderão ser resolvidos, e os pontos restantes passam a ser objeto de avaliação quando houver interesse.

Destacamos que a metodologia construtivista se opõe ao paradigma científico, quando nega a existência de uma realidade objetiva, afirmando que as realidades são construções sociais mentais e que existem tantas quanto o número de indivíduos.

Um dos pontos que causa certa aversão a adoção do método construtivista responsivo pelos que propõem dos modelos convencionais, é a aceitação de que não pode haver nenhuma certeza no modo como as coisas ocorrem, não existem nenhuma verdade objetiva onde as 
investigações possam convergir, essa ambiguidade traz a pergunta "se as avaliações não podem compreender a verdade, por que fazê-las?”. essa metodologia também pressupõe uma renuncia de controle sobre o processo, suposto que os grupos de interesse desempenhem as mesmas funções definidas em todos os estágios com o avaliador e o cliente. Além de que comprometerse com essa metodologia significa abandonar a suposição de que é possível encontrar intervenções.

A quarta geração apresenta como benefícios: substituir a certeza pela relatividade, o controle pela concessão de poder, a explicação generalizada pela compreensão local e a arrogância pela humildade. Utilizando a metodologia construtivista que é pautada em paradigmas - definido como visão de mundo - que negam a existência de uma realidade objetiva, em vez disso, diz que as realidades são construções sociais mentais em proporção igualitária ao número de individuos no mundo. Sendo assim, a avaliação, segundo Guba e Lincoln (1986), produz dados nos quais fatos e valores estão embaraçosamente relacionados, onde o críticar é importante no processo de avaliação oferecendo fundamentação para as acepções atribuidas.

\section{METODOLOGIA}

Realizamos uma pesquisa aplicada que, segundo Goldenberg (2004), são as pesquisas que se baseiam no desejo de conhecer melhor algo. Esta pesquisa também de ordem qualitativa, de acordo com Minayo (2002, p. 22) é abordagem que "aprofunda-se no mundo dos significados das ações e relações humanas.” Sob abordagem descritiva que de acordo com Gil (2010, p. 28) são aquelas que têm por "objetivo primordial a descrição das caracteristicas de determinada população ou fênomeno ou estabelecimento de relações entre variáveis." Os sujeitos da pesquisa são professores do ensino superior da rede pública federal de ensino - Selecionamos como sujeitos participantes da pesquisa, professores que atuam em instituição federal de ensino superior.

Para obtenção de dados foi realizada o envio de um formulário, no período de 01/10/2021 a 06/10/2021, contendo perguntas relativas a aplicabilidade da avaliação em sala de aula, com a finalidade de coletar uma amostragem com os professores do Ensino Superior da licenciatura plena em Química. As respostas do formulário foram tabuladas e serão analisadas a seguir.

\section{RESULTADOS E DISCUSSÃO}

Foi encaminhado um formulário aos professores, através do Google Forms, de uma 
instituição de ensino federal, contendo perguntas relativas ao seu trabalho de sala de aula com a avaliação.

Ao perguntarmos a opinião dos professores sobre o que eles compreendem por avaliação (quadro 1) obtivemos respostas parecidas, tratando a avaliação como um meio para a clareza do processo de ensino e de aprendizagem. Como descrito por Viana (2014), a avaliação é um processo, onde avaliadores e estudantes ensinam e aprendem uns com os outros, simultaneamente. Sendo um processo de troca, em que o consenso tem por objetivo uma expansão da visão sobre o objeto de avaliação e o resultado é continuamente reajustavél, podendo ser reconstruido, revisado ou até mesmo substituído, caso haja necessidade.

Quadro 1: Respostas dos professores de Química de uma instituição federal de Ensino Superior.

\begin{tabular}{|c|r|}
\hline \multicolumn{2}{|c|}{ 1. O que você compreende por avaliação? } \\
\hline Respondente 01 & Elemento do processo de ensino e aprendizagem \\
\hline Respondente 02 & Processo. Caminho para entender o ensino e a aprendizagem \\
\hline Respondente 03 & $\begin{array}{r}\text { É o momento, ou período, em que podemos ter uma clareza da efetividade } \\
\text { do processo de ensino e aprendizagem. Nessa perspectiva, concebo a } \\
\text { avaliação como sendo de ambos sujeitos envolvidos desse processo: } \\
\end{array}$ \\
\hline
\end{tabular}

\section{Fonte: Própria (2021)}

Em uma perspectiva Diagnóstica, na medida em que investiga e caracteriza o perfil e/ou o desenvolvimento dos estudantes neste processo, com fins de possibilitar uma mediação pelo professor, ante suas dificuldades e a não-aprendizagem, subsidiando-o no planejamento de sua intervenção.

Em uma perspectiva Processual, quando reconhece que a aprendizagem não acontece pela simples absorção de conhecimentos, mas considera professor e estudante como participantes de um processo construtivo por meio do diálogo. Em uma perspectiva Formativa, fornecendo ao estudante a plena consciência acerca da atividade que desenvolve e dos objetivos da aprendizagem, podendo este participar na regulação da aprendizagem de forma consciente. Quando o estudante expressa seus saberes, possibilita ao professor atuar de forma investigativa na construção de alternativas de ensino como ação transformadora (PPC, 2013)

Os professores entendem o papel do estudante como sendo um observador ativo que auxilia no retorno sobre o andamento do processo de ensino e de aprendizagem (quadro 2). A fala do Respondente 03 chamou minha atenção ao declarar “... agente de discussão junto com o professor, apontando possibilidades desses instrumentos." Avaliação é uma atividade de 
empoderamento para todas as partes envolvidas, é um processo colaborativo em que o estudante - um individuo totalmente ativo - compartilha junto ao professor o controle sobre as decisões nas metodologias aplicadas, buscando-se um consenso de ambas as partes.

Avaliação também é um processo de partilha de responsabilidade, em vez de atribuição. é uma troca de conhecimento entre avaliadores e avaliados (Viana, 2014). Ainda sobre o respondente 03, quando perguntado como ocorre sua avaliação em sala de aula (quadro 3) reforça a discussão acima quando diz: “... Tenho, dado abertura para que os estudantes opinem como e quando, aplicar o instrumento avaliativo. Algumas disciplinas, avalio o processo de aprendizagem do estudante, oportunizando a expressão do seu conhecimento para além da "prova escrita." Mostrando-se adepto do pensamento de Guba e Lincoln (1989) sobre o papel do estudante no processo avaliativo.

Quadro 2: Respostas dos professores de química de uma instituição federal de ensino superior.

\begin{tabular}{|c|c|}
\hline \multicolumn{2}{|c|}{ 2. Qual o papel do estudante no processo avaliativo? } \\
\hline Respondente 01 & Responsável por um dos feedback do processo de ensino e aprendizagem \\
\hline Respondente 02 & Um espectador que caminha para o protagonismo \\
\hline Respondente 03 & $\begin{array}{c}\text { Acredito que o rendimento alcançado pelos estudantes no instrumento } \\
\text { avaliativo, possa ser parâmetro para nortear uma possível adequação da } \\
\text { didática da aula, bem como, agente de discussão junto com o professor, } \\
\text { apontando possibilidades desses instrumentos. }\end{array}$ \\
\hline
\end{tabular}

Fonte: Própria (2021)

De acordo com as respostas, os professores externaram buscar ir além das provas escritas, procurando extrair do estudante o máximo de aproveitamento desse processo de ensino e de aprendizagem (quadro 3).

A Proposta Pedagógica do Curso de Licenciatura Plena em Química prevê uma avaliação contínua, assumindo de forma integrada as funções diagnóstica, processual, formativa e somativa, que devem ser utilizadas como princípios para a tomada de consciência da prática, levando em consideração o predomínio dos aspectos qualitativos sobre os quantitativos.

Avaliação é um processo contínuo, recursivo e divergente, o que se é obtido do processo avaliativo cria construtos sociais passíveis a reconstrução. Uma boa avaliação não se encerra em si mesma, ela desencadeia mais questões, além das levantadas em sua aplicação. Todo o processo na avaliação é importante, desde sua concepção até a obtenção dos resultados, nada é desconsiderado, nenhuma parte do processo avaliativo é sem valor.

A avaliação é um processo que agrupa a coleta de dados e interpretação de dados em 
um todo. $\mathrm{O}$ avaliador é como um analista de dados, um historicista e um iluminador, um maestro do processo avaliativo, é um mediador na execução da avaliação, um coparticipante no processo. O avaliador não pode assumir o papel de supremo no processo da avaliação, ao contrário, deve se mostrar humilde e aberto a escutar opiniões (Viana, 2014).

Quadro 3: Respostas dos professores de química de uma instituição federal de ensino superior.

\begin{tabular}{|c|c|}
\hline \multicolumn{2}{|r|}{ 3. Como ocorre sua avaliação em sala de aula? } \\
\hline Respondente 01 & $\begin{array}{l}\text { De maneira formal e informal. Formal: Realização de provas escritas, } \\
\text { seminários e participação nas aulas. Informal: Questionamentos e interações } \\
\text { durante as apresentações de conteúdos nas aulas. }\end{array}$ \\
\hline Respondente 02 & Procuro dentro da medida do possível realizar uma avaliação formativa \\
\hline Respondente 03 & $\begin{array}{l}\text { As concepções que mencionei anteriormente, foram descritas para um } \\
\text { cenário escolar que esteja apta para ampliar o conceito tradicional de } \\
\text { avaliação, como ação unilateral. Tenho, dado abertura para que os } \\
\text { estudantes opinem como e quando, aplicar o instrumento avaliativo. } \\
\text { Algumas disciplinas, avalio o processo de aprendizagem do estudante, } \\
\text { oportunizando a expressão do seu conhecimento para além da "prova } \\
\text { escrita." }\end{array}$ \\
\hline
\end{tabular}

Fonte: Própria(2021)

Ao serem perguntados sobre quais os instrumentos avaliativos utilizavam (quadro 4), como já visto nas respostas anteriores, os professores aplicam vários métodos avaliativos para a construção dos seus arcabouços avaliativos. Nos respondentes 1 e 2 destacam-se a participação em aula, que é instigada pelo professor visto nas falas "... participação nas aulas, questionamentos e interações durante as apresentações de conteúdos nas aulas"; ".. .no momento da regência de sala de aula, incentivo à participação do estudante, elaborando perguntas orais para a turma; tenho comumente tenho explorado a problematização e o choque cognitivo por situações aparentemente paradoxais e imprevisíveis. Nas turmas do Ensino Médio, avalio qualitativamente essa participação do estudante aula a aula."

A avaliação é diagnostica, formativa, reguladora, democrática e participativa, o professor assume o papel de mediador atenuando a discussão entre os avaliados, e deve possuir não somente domínio sobre os conteúdos, mas também qualidades interpessoais como paciência, humildade, abertura, adaptabilidade e senso de humor. As decisões estabelecidas com base na negociação e diálogo. Há uma preocupação com a compreensão do estudante. Busca-se respostas críticas e reflexivas (Viana, 2014). 
Dentre os metodos utilizados pelo professor respondente 2, destacou-se o trabalho em equipe e a autoavaliação (quadro 4). A avaliação é um processo sóciopolítico, que traz a sublimação do conhecimento através da interação social, dessa forma ela é constantemente reconstruída e reciclada, levando em consideração o indivíduo e suas interações socias, sendo assim, o contexto político e cultural do avaliado também são observados.

Quadro 4: Respostas dos professores de Química de uma instituição federal de Ensino Superior.

\begin{tabular}{|c|c|}
\hline \multicolumn{2}{|c|}{ 4. Quais os instrumentos avaliativos que você utiliza em suas aulas? } \\
\hline Respondente 01 & $\begin{array}{r}\text { Realização de provas escritas, seminários e participação nas aulas, } \\
\text { Questionamentos e interações durante as apresentações de conteúdos nas } \\
\text { aulas. }\end{array}$ \\
\hline Respondente 02 & $\begin{array}{c}\text { Seminários, formulação e resolução de questões, simulados, trabalho em } \\
\text { equipe, auto-avaliação }\end{array}$ \\
\hline Respondente 03 & $\begin{array}{c}\text { Além da avaliação escrita; no momento da regência de sala de aula, } \\
\text { incentivo à participação do estudante, elaborando perguntas orais para a } \\
\text { turma; tenho comumente tenho explorado a problematização e o choque } \\
\text { cognitivo por situações aparentemente paradoxais e imprevisíveis. Nas } \\
\text { turmas do Ensino Médio, avalio qualitativamente essa participação do } \\
\text { estudante aula a aula. No tocante à avaliação das estratégias didáticas, tenho } \\
\text { analisado graficamente o rendimento da turma e entre as turmas, visando } \\
\text { encontrar pontos que requerem mudanças. }\end{array}$ \\
\hline
\end{tabular}

Fonte: Própria (2021)

O PPC salienta que os critérios avaliativos adotados dependerão dos objetivos de ensino e saberes pretendidos para cada momento, os chamados ciclos avaliativos. O professor, dessa maneira, precisará elencar em seu plano os critérios que respondam às expectativas iniciais, garantindo, porém, a flexibilidade necessária em seu planejamento para que a avaliação supere momentos pontuais e se configure como um processo de investigação, de respostas e de regulação, tanto do ensino como da aprendizagem. Devendo considerar a educabilidade, em que todo estudante é capaz de aprender, como um dos objetivos a ser atingido. A avaliação, nessa perspectiva, considera os ritmos e caminhos particulares que são trilhados pelos estudantes, acolhendo as diferenças do processo de ensino e aprendizagem (PPC, 2013).

As avaliações devem ser continuamente recicladas e atualizadas, segundo a proposta de Guba e Lincoln, pois seus resultados denotam mais perguntas que podem servir como objetos para a próxima avaliação, não pode ser tratada de maneira generalizada, pois contextos 
diferentes geram realidades diferentes. O objeto da avaliação, porém, pode ser adaptado a vários cenários. Na fala do respondente 3 “... No tocante à avaliação das estratégias didáticas, tenho analisado graficamente o rendimento da turma e entre as turmas, visando encontrar pontos que requerem mudanças." Percebemos essa reciclagem e atualização continua em seu processo avaliativo.

Avalia-se, portanto, para constatar os conhecimentos dos estudantes em nível conceitual, procedimental e atitudinal, tendo como princípios norteadores desse processo: o estabelecimento de critérios claros, expostos no plano da disciplina; consideração da progressão das aprendizagens a cada etapa do processo de ensino; o necessário respeito à heterogeneidade e ritmo de aprendizagem dos estudantes; as possibilidades de intervenção e/ou regulação na aprendizagem, considerando os diversos saberes; a consideração do desenvolvimento integral do estudante e seus diversos contextos por meio de estratégias e instrumentos avaliativos diversificados que se complementam.

Ressaltamos que, para que a avaliação caracterize-se de forma ética deve centrar-se em parâmetros claramente delineados e em julgamentos sobre os processos de ensino e de aprendizagem, neles incluindo não apenas o estudante, mas também os docentes. Assim, ao planejar o processo avaliativo, considerando a complexidade da prática pedagógica. (PPC, 2013)

As respostas apresentas pelos professores dialogam com o PPC do curso de licenciatura em Química, da instituição federal em que foi realizada a pesquisa. Observou-se que os professores busam aplicar vários métodos avaliativos, bem como dialogam com os estudantes sobre a execução das avaliações.

\section{CONCLUSÕES}

A Proposta Pedagógica do Curso de Licenciatura Plena em Química prevê uma avaliação contínua, assumindo de forma integrada as funções diagnóstica, processual, formativa e somativa, que devem ser utilizadas como princípios para a tomada de consciência da prática, levando em consideração o predomínio dos aspectos qualitativos sobre os quantitativos. Avaliase, portanto, para constatar os conhecimentos dos estudantes em nível conceitual, procedimental e atitudinal.

Todavia, para que a avaliação caracterize-se de forma ética deve centrar-se em parâmetros claramente delineados e sem julgamentos sobre os processos de ensino e de aprendizagem, neles incluindo não apenas o estudante, mas também os docentes. É importante salientar que os critérios avaliativos adotados dependerão dos objetivos de ensino e saberes 
pretendidos para cada momento, os chamados ciclos avaliativos. O professor, dessa maneira, precisará elencar em seu plano os critérios que respondam às expectativas iniciais, garantindo a flexibilidade necessária em seu planejamento para que a avaliação supere momentos pontuais e se configure como um processo de investigação, de respostas e de regulação.

A avaliação, nessa perspectiva, considera os ritmos e caminhos particulares que são trilhados pelos estudante, acolhendo as diferenças do processo de ensino e aprendizagem. Por esse motivo, faz-se necessário uma diversidade de instrumentos que se comunique e se complemente, possibilitando uma visão contínua e ampla das aprendizagens, que busca dialogar com uma pedagogia diferenciada, em um currículo flexível e contextualizado. Nessa perspectiva, propõe-se que o professor possa considerar as múltiplas formas de avaliação, por meio de instrumentos diversificados, os quais lhe possibilitem observar melhor o desempenho do estudante nas atividades desenvolvidas (PPC, 2013)

Com o objetivo de categorizar a perspectiva da avaliação no PPC da Licenciatura em Química da Rede Federal de acordo com as Gerações da Avaliação; identificar as práticas avaliativas do professor e suas relações com as orientações contidas no PPC, a pesquisa mostrou-se contrária a hipótese de que as práticas avaliativas na formação de professores caminham para a materialização da avaliação de quarta geração. Os respondentes apresentaram inclinações a seguda geração e terceira geração da avaliação.

$\mathrm{O}$ estudante na segunda geração tem o papel passivo, sendo um receptor, a fala " $U m$ espectador que caminha para o protagonismo" evidência a inclinação do respondente a segunda geração da avaliação. Nas falas “...rendimento alcançado pelos estudantes no instrumento avaliativo, possa ser parâmetro para nortear uma possível adequação da didática da aula..." (sobre o papel do estudante, quadro 2) "Procuro dentro da medida do possível realizar uma avaliação formativa" (sobre como ocorre a avaliação em sala, quadro 3) "No tocante à avaliação das estratégias didáticas, tenho analisado graficamente o rendimento da turma e entre as turmas, visando encontrar pontos que requerem mudanças." (sobre instrumentos avaliativos utilizados, quadro 4), comportam a finalidade da avaliação de segunda geração que é de aperfeiçoamento do currículo, o que hoje é denominada avaliação formativa.

Na terceira geração da avaliação o estudante é ativo e partipante na ação avaliativa, tais traços podem ser percebidos nas falas "Responsável por um dos feedback do processo de ensino e aprendizagem" "agente de discussão junto com o professor, apontando possibilidades desses instrumentos." (sobre o papel do estudante, quadro 2) “...Questionamentos e interações durante as apresentações de conteúdos nas aulas." “...Tenho, dado abertura para que os estudantes opinem como e quando, aplicar o instrumento avaliativo. Algumas disciplinas, avalio o 
processo de aprendizagem do estudante, oportunizando a expressão do seu conhecimento para além da "prova escrita." “...no momento da regência de sala de aula, incentivo à participação do estudante, elaborando perguntas orais para a turma [...] Nas turmas do Ensino Médio, avalio qualitativamente essa participação do estudante aula a aula..." (sobre instrumento de avaliação utilizado, quadro 4). Mostrando assim, ter-se uma preocupação com a compreensão do estudante, característica marcante na terceira geração da avaliação.

Os professores entrevistados demostrarm-se, em suas falas, andar em acordo com a materialização do proposto no PPC do curso de licenciatura em Química, em que prevê que a avaliação deve ser diagnóstica, processual e formativa, levando em consideração a participação do estudante bem como sua compreensão.

Pelo curto espaço de tempo não foi possível aprofundar-se na pesquisa, com questões como observação do que foi descrito no questionário e se aplica em sala de aula.

\section{REFERÊNCIAS}

GUBA, E. G.; LINCOLN, Y. S. Fourth generation evaluation. Newbury Park, London, New Delhi: Sage, 1989.

HOFFMAN, J. Avaliação mediadora: uma prática em construção da pré-escola à universidade. Porto Alegre: Mediação, 2001.

LIMA, K. S. Compreendendo as concepções de avaliação de professores de física através da teoria dos construtos pessoais. Recife, 2008. 163 p. Dissertação (Ensino das Ciências). Departamento de Educação, UFRPE, 2008.

SALES, E. S.; MONTEIRO, I. G. S.; LIMA, K. S. Formação de professor, diretrizes da Educação brasileira para o ensino de Química e Avaliação: saberes docentes essenciais à formação docente. In: VII Colóquio Internacional Educação e Contemporaneidade, 2013, São Cristóvão - SE. Anais do Colóquio Internacional Educação e Contemporaneidade, 2013.

NARDI, R.; CORTELLA, B. S. C. Formação de professores de Física: das intenções legais ao discurso dos formadores. In: XVI Simpósio Nacional de Ensino de Física, 2005, Rio de Janeiro. Caderno de Resumos. São Paulo - SP: Sociedade Brasileira de Física, 2005. v. 1. p. 175-175, 2005.

IFPE. Projeto Pedagógico do curso. Instituto Federal de Pernambuco - IFPE, 2013. Disponivel em:

https://www.ifpe.edu.br/campus/vitoria/cursos/superiores/licenciaturas/quimica/projetopedagogico/PROJETOPEDAGGICO2013VSA1810.pdf/view 